\title{
Frankenstein: das páginas do romance para às telas de cinema
}

\section{Frankenstein: from the pages of the novel to the movie screens}

Laura de Almeida*

Arthur Yerro Oliveira Santos*

* Docente no curso de Letras do Departamento de Letras e Artes da Universidade Estadual de Santa Cruz (DLA/UESC). E-mail: prismaxe@gmail.com

"** Graduando em Letras da Universidade Estadual de Santa Cruz (UESC). Ex-bolsista PIBIC/ FAPESB. E-mail: arthur.yerro02@gmail.com 
Resumo: 0 presente estudo aborda a intertextualidade entre o texto literário Frankenstein, ou O Prometeu Moderno (Shelley 2017), o filme adaptado de tal texto (Whale 1931) e o filme Victor Frankenstein (McGuigan 2015). Objetivamos destacar as possíveis áreas de convergência e divergência de significado entre o texto original literário e filmes adaptados a partir dele. Adotamos os conceitos de responsabilidade (Ruiz 2009) e o imaginário (Araújo 2014), nas teorias de linguagem (Costa 2002; Spica 2015) e na trajetória da Criatura (Lucas 2017). Além disso, nos baseamos nas teorias de adaptação de Hutcheon (2006), comparando-as com visões semióticas entre livros e filmes (Jeha 2004) e na transformação crítica (Wesonga 2017). Observamos que o leitor da obra literária poderá compreender melhor e interagir com significados alternativos que os filmes criam de textos literários.

Palavras-chave: Estudos da Adaptação; Frankenstein; Mary Shelley; Intertextualidade; James Whale; Victor Frankenstein; Paul McGuigan.

Abstract: This study deals with the intertextuality between the literary text Frankenstein, or the Modern Prometheus (Shelley 2017), the movie adapted from the text (Whale 1931) and the film Victor Frankenstein (McGuigan 2015). We highlight possible areas of convergence and divergence of meaning between the written work and the movies adapted from it. We adopted the responsibility concept (Ruiz 2009) and research on the imaginary (Araújo 2014) and based on language theories (Costa 2002; Spica 2015) and in the Creature's trajectory (Lucas 2017). In addition, we are utilizing adaptation theories from Hutcheon (2006), comparing semiotic views between books and films (Jeha 2004) and in the critical transformation (Wesonga 2017). We highlight the literary reader may better understand and interact with of literary texts' alternate meanings created by films.

Keywords: Adaptation Studies; Frankenstein; Mary Shelley; Intertextuality; James Whale; Victor Frankenstein; Paul McGuigan.

TradTerm, São Paulo, v.38, fevereiro/2021, p. 337-360

Número Especial - III JOTA

www.revistas.usp.br/tradterm 


\section{Introdução}

O romance Frankenstein ou O Prometeu Moderno (SHelley 1831) é considerado um marco da Ficção Científica, pois se volta para o mundo da ciência, sua organização e produção, ideais de conhecimento e avanços técnicos. A obra é vista como o primeiro romance gótico-psicológico, no qual é mantida a ambientação exótica, agora relacionada ao mundo da ciência.

Primeira das três grandes narrativas do gênero gótico, foi lançada em 1818, mas só na introdução da edição de 1831 Mary Shelley comenta a gênese da obra. Esta versão é a utilizada como objeto deste trabalho, a partir da tradução lançada em 2017 pela editora brasileira Darkside. A narrativa é dividida entre o Capitão Walton, Victor Frankenstein e sua Criatura não nomeada, chamada recorrentemente de Monstro pelo próprio criador, e é contada a partir de cartas do narrador-protagonista para um personagem que assume a postura do leitor. No livro, o jovem estudante de medicina Victor Frankenstein ${ }^{1}$ dá vida a um ser criado a partir de cadáveres humanos. Ao ver que a experiência não saiu como o planejado, fica horrorizado e abandona sua própria criação.

Outro tema abordado é a criação que se volta contra seu criador e pode ser compreendida de duas formas: nos filmes, evidenciado por uma experiência científica que escapa ao controle do cientista; no romance, por este ter se tornado mais famoso que sua criadora, devido ao fato de poucos lembrarem que Mary Shelley foi a autora da obra.

Este trabalho tem o objetivo de explicitar os conceitos de adaptação e transposição usados nos filmes Frankenstein (1931), dirigido por James Whale, e Victor Frankenstein (2015), de Paul McGuigan, em relação à obra literária de Mary Shelley. A presente análise está embasada no estudo de Hutcheon (2006: 177), segundo a qual encontramos estudos existentes especialmente na literatura e em filmes. Como afirma a teórica, adaptação não se refere apenas a obras literárias e filmes, pois, podemos adaptar vários tipos de mídias, como histórias em quadrinhos, séries de televisão, games, rádio, dentre outras. Hutcheon diz ser uma obra adaptada aquela que deu origem à

\footnotetext{
${ }^{1} \mathrm{Na}$ cultura popular, o nome do cientista se transformou em referência à criatura.
}

TradTerm, São Paulo, v.38, fevereiro/2021, p. 337-360

Número Especial - III JOTA

www.revistas.usp.br/tradterm 
outra, e que o termo adaptação se refere tanto ao processo quanto ao produto, evitando usar o termo 'texto original' o que poderia levar a crer que ele é melhor pelo fato de ter sido criado antes. Como produto, uma adaptação é uma transposição de um trabalho particular, uma transcodificação que pode envolver a mudança de um livro para um filme; o caso que analisamos foi a transposição da obra escrita para o filme. Enquanto processo de criação, o ato da adaptação envolve sempre a interpretação e a recriação, ou seja, no filme observamos algumas cenas que não ocorrem na obra, como veremos posteriormente (HUTCHEON 2006: 7-8).

Em relação aos diferentes atos de criação, Robert Wesonga (2017) discute a transformação crítica, em que o texto literário e filme adaptado são diferentes meios de comunicação, considerando que os filmes usam de técnicas, tais como som, iluminação, música, flashback, narrativa em off, para compensar a descrição narrativa usada nos textos literários. Completando o pensamento, Julio Jeha (2004) apresenta uma comparação das visões semióticas entre livros e filmes, pois ambos são duas mídias distintas e, portanto, requerem interpretantes diferentes: trata-se de um processo de tradução que se transforma em outro signo, um texto ou um filme.

A metodologia de pesquisa, de cunho bibliográfico, busca estabelecer pontos de convergência entre a obra e os filmes, evidenciando as relações entre a obra escolhida e suas transposições. Após breve introdução da profusa fortuna crítica, os filmes foram comparados, focando duas personagens: Victor e sua Criatura.

\section{Linguagem e conhecimento em Frankenstein: o signo pela Criatura}

O que é linguagem e qual o seu propósito na formação de um indivíduo? A linguagem, vista por um aspecto cognitivo, é importante ao se pensar a racionalidade; também o processo de integração de um indivíduo na sociedade em que se encontra enquanto forma de comunicação. De acordo com Aline de Caldas Costa (2002:11)

TradTerm, São Paulo, v.38, fevereiro/2021, p. 337-360

Número Especial - III JOTA

www.revistas.usp.br/tradterm 


\begin{abstract}
a linguagem, examinada sob o ponto de vista evolucionista, coloca o homem numa linha tênue entre a racionalidade e a alienação. Surgida de uma necessidade humana, em relacionar-se com a natureza e os outros homens, a linguagem se apresenta como instrumento racional do inter-relacionamento. Tal racionalidade, por sua vez, levou o homem a buscar maneiras de situar-se enquanto sujeito, através de um universo de costumes e tradições, que o identificasse quando inserido em um grupo.
\end{abstract}

Em Frankenstein de Shelley, a Criatura vaga pelo mundo após ter abandonado o antigo laboratório (cenário gótico do romance e espaço da manifestação do horror) do seu criador e se depara com uma pequena casa no campo, tendo assim seu primeiro contato com humanos - o velho cego De Lacey e os filhos - e suas emoções. Ao perceber nelas as características que lhe faltavam, coisas nas quais nunca havia pensado, a visão a deixa atordoada. Comovida, a Criatura diz sentir uma mistura de dor e prazer que podem estar relacionados ao fato de, mesmo podendo sentir emoções humanas, reconhecer que estas não a livram de sua aparência, da autocrítica e das críticas de outras pessoas desde que foi abandonada por seu criador. Assim, ela começa a perceber as mudanças constantes que estão acontecendo em sua personalidade, ao aprender sobre a realidade humana e o mundo no qual foi trazido à vida.

Após descobrir a cabana do velho De Lacey e seus filhos, a Criatura afirma ter muita dificuldade para entender os significados dos sons pronunciados por eles. Ela diz que se aprimorou para entender o que eles diziam, e somente se revelaria a eles se dominasse a linguagem (ou seja, o signo). A Criatura aprende a falar por perceber que, por meio da comunicação, pode expressar seus Sentimentos, bem como por se afeiçoar aos aldeões e querer se comunicar com eles de alguma forma.

A respeito da comunicação, Julio Plaza afirma que (1987: 21), "é algo que, sob certo aspecto, dirige-se a alguém, isto é, cria na mente dessa pessoa um signo equivalente ou talvez um signo mais desenvolvido". A partir de suas primeiras experiências, a Criatura estabelece contato com outros signos, criando um conhecimento inicial para o entendimento da humanidade. Este se aprofunda por intermédio de uma maleta de livros que a Criatura achara e das

TradTerm, São Paulo, v.38, fevereiro/2021, p. 337-360

Número Especial - III JOTA

www.revistas.usp.br/tradterm 
páginas do livro que Felix, um dos habitantes da cabana, lia. Dentre as leituras que influenciaram seu aprendizado da linguagem temos os poemas $A$ Balada do Velho Marinheiro (1898), de Samuel T. Coleridge e O Paraíso Perdido (1667), de John Milton; os romances Caleb Williams (1794) e Maria (1798), escritos por William Godwin e Mary Wollstonecraft (pais da autora) e estudos científicos e filosóficos. Sem saber o que é humanidade ou sociedade, a Criatura toma contato com essas noções ao ouvir a leitura de Ruínas do Império de Constantin Volney (1792); e ao ouvir as Vidas Paralelas de Plutarco (primeira edição inglesa, 1579) vai entender sobre a república.

À medida que aprende o idioma falado pelos moradores da cabana, a Criatura atribui significado aos seus pensamentos, e sua produção de ideias aflora. Ela se torna uma entidade com opiniões e moral, com o conhecimento que levaria ao discernimento de suas emoções e o que elas representavam em relação às emoções humanas. Contudo, esse conhecimento é parcial, pois ele se faz a partir das impressões da Criatura do que é o ser humano, a própria humanidade, a sociedade, e até a autoridade superior, 'Deus', a partir da leitura dos livros.

A Criatura descobre, ao observar as conversas dos aldeões, como a linguagem facilita a interação entre as pessoas e pressupõe que isso a auxiliaria no processo de aceitação como um ser social. Costa (2002: 11) denota que a linguagem se torna não apenas um símbolo do conhecimento que a criatura reproduzia e utilizava, como também um meio para obter mais saberes e entender como a humanidade funciona e é construída.

Tais reflexões levam a Criatura a se compreender em relação ao mundo: a se ver como alguém 'gerado' por um criador, e este é tido por ela como um ser superior; ou a não parecer pertencer a nenhum lugar enquanto aparentemente todos tinham um para si. Até os mais pobres, como o velho De Lacey e os seus filhos, seres que tinham 'família' e emoções, e viviam sob certos dogmas de bondade e coletividade. A Criatura, ensinada sobre o mundo apenas por pessoas que a atacaram e a rejeitaram, demonstrava notas de pensamento crítico construído através dos signos que a cercavam:

TradTerm, São Paulo, v.38, fevereiro/2021, p. 337-360

Número Especial - III JOTA

www.revistas.usp.br/tradterm 
Seria o homem, ao mesmo tempo, de fato, tão poderoso, virtuoso e magnífico e, no entanto, tão vicioso e desprezível? Pareceu-me, simultaneamente, um mero herdeiro do princípio do mal e, por outro lado, tudo o que pode ser concebido como nobre e divino. Ser um homem grande e digno é a maior honra que pode caber a um ser sensível; ser vil e impuro, como muitos o foram, parece a mais baixa degradação, uma condição mais abjeta que a de uma toupeira cega ou a de um verme inofensivo. Por muito tempo não pude conceber como um homem poderia assassinar o próximo ou mesmo por que havia leis e governos, mas quando ouvi detalhes dos vícios e das matanças, deixei de pensar e afastei-me com desgosto e aversão (SHELLEY 2017: 131).

A partir do conhecimento do mundo em que tentava se inserir, a Criatura desenvolvia emoções semelhantes às humanas. Buscando formar seu próprio juízo de valor, começava a discernir as situações e a trabalhar nelas o entendimento sobre a moral oscilando em relação à dualidade bem/mal existente nos homens. Não compreendia as características presentes no caráter humano e questionava-se sobre a idealização de ser igual e o que isso significaria para si mesma em relação às rejeições sofridas por parte de outras pessoas, assim como as rejeições criadas em seu interior pelas instabilidades do homem. Como poderia o humano ser tão desumano a ponto de matar os seus iguais, travar guerras e praticar males a bel-prazer e mesmo assim merecer mais que um ser tão próximo ou além das capacidades humanas como a Criatura?

Ao reconhecer seu aspecto monstruoso presente no contexto social em que se encontra, a Criatura começa a nutrir os mesmos sentimentos negativos, refletindo sobre os conceitos impostos e presentes de seu distante contato com a humanidade.

O que a Criatura aprendeu acerca dos homens e da natureza humana aconteceu sempre sob o signo do afastamento físico, sem o toque do calor humano, sem um frente a frente, olhos nos olhos. Essa privação do contacto físico e do olhar humanos foi certamente perniciosa e traumatizante para a Criatura, especialmente quando a isso se acrescentava uma reacção automática e imediata de repúdio e de repugnância face à sua fealdade e ao seu gigantismo (ARAÚJo 2014: 05).

Dessa forma, o novo conhecimento motivou a Criatura a estabelecer mais paralelos entre a sua existência e as de outrem: novos questionamentos

TradTerm, São Paulo, v.38, fevereiro/2021, p. 337-360

Número Especial - III JOTA

www.revistas.usp.br/tradterm 
nasceram, guiando-a para uma nova linha de pensamento sobre ser o que representava e o seu propósito social. Começou a notar-se diferente daqueles a quem tanto buscava se assimilar, não apenas em relação aos preceitos estéticos ou intelectuais, mas às características humanas exteriores que faltavam em si, o que quer principalmente é ser aceita apesar de sua deformidade. Acredita que o domínio da linguagem facilite sua inserção em um meio social. Após ler Paraíso Perdido começa a pensar sobre sua identidade, relacionando-a com o conflito entre o Bem e o Mal e descobre ter sido rejeitada e abandonada por seu criador, o que a leva a se revoltar contra os seres humanos e a odiá-los.

De Lacey e os seus filhos, Felix e Agatha, assim como a prometida do homem, a noiva árabe, Safie, são aqueles de quem a Criatura sente-se próxima, ela os admira como seres cheios de bondade. A aquisição da linguagem é vista como um esforço para se identificar com eles. Contudo, além dos sentimentos de afeto, a leitura dos livros a ajuda a entender mais um conjunto de emoções existentes em seu íntimo, negativas e nocivas. A cada reflexão e conhecimento, a Criatura percebe as reações de repulsa e de horror. O fato de ser rejeitada a leva a rejeitar a todos, ao perceber como/quanto diferem fisicamente. No entanto, se identifica com os humanos nos defeitos como a inveja e o ódio.

Quando ela se sente de alguma forma abandonada novamente, primeiro por Victor, o seu criador, rebate o sentimento, deixando-se levar pelas novas emoções em ataques de raiva e fúria:

Pela primeira vez, os sentimentos de vingança e de ódio encheram meu peito e não lutei para controlá-los, mas, permitindo-me dar vazão ao fluxo, voltei a mente para pensamentos de injúrias e morte. Quando pensava em meus amigos, na voz suave de De Lacey, nos olhos gentis de Ágatha e na beleza rara da árabe, essas considerações se esvaíam e uma torrente de lágrimas, de certo modo, me acalmava. Entretanto, mais uma vez, quando lembrava que tinham me tratado com desprezo e me deserdado, a ira retornava, um furor de raiva; e, impossibilitado de danificar qualquer coisa humana, voltei a fúria para objetos inanimados (SHELLEY 2017: 147).

TradTerm, São Paulo, v.38, fevereiro/2021, p. 337-360

Número Especial - III JOTA

www.revistas.usp.br/tradterm 
Pode-se notar que a Criatura não é ignorante quando começa a entender os próprios sentimentos, possui noções sobre certo e errado, bem e o mal. Essas emoções, contudo, resultado de seu entendimento das relações humanas, mas exaltadas quando o indivíduo em questão era o próprio. Motivada pelo sentimento de vingança pela rejeição de seu criador, mata os entes queridos dele para fazê-lo sofrer e sentir igualmente infeliz.

Segundo Ricardo Lucas e Felipe Rodrigues (2017: 25), que identificam em sua análise a trajetória de vida do ser criado por Victor, isolamento "se dá não apenas no âmbito físico, mas também, cultural, social e psicológico. 0 problema não é tanto se comunicar, mas se identificar com alguém, fato dificultado inclusive por sua aparência física, admitindo a inferioridade junto ao seu criador, e tem consciência de necessitar de sua ajuda para sobreviver.

\section{As responsabilidades de Victor como pai e o desenvolvimento da criatura}

Ao voltar para o país de origem e saber da morte de seu irmão mais novo, Victor se enche de melancolia; mas, quando nota a Criatura ao longe, surge um novo sentimento: a repulsa, pois o cientista acha que o monstro representa o fracasso de seu experimento científico e é uma aberração da Natureza. Identifica-se, assim, um dos primeiros momentos em que Frankenstein começa a atribuir a razão de suas amarguras ao indivíduo por ele construído, o que incita reflexões no contexto homem-monstro, em que a criação é apenas um espelho do criador. 0 cientista se recusa a analisar essas ideias, concebendo a Criatura então como 'medonha', 'desgraçada', 'demônio' - adjetivos usados para desumanizar o ser e tratá-lo como nada mais que um monstro. Observamos que o trata dessa forma, por enxergá-lo como uma aberração, apenas uma criatura monstruosa. Em certos aspectos em seu excesso de racionalismo e frieza, Victor é tão ou mais 'monstruoso' que a Criatura, pois, para fazer suas experiências, ele não hesitou em violar túmulos e negociar a compra de corpos humanos.

TradTerm, São Paulo, v.38, fevereiro/2021, p. 337-360

Número Especial - III JOTA

www.revistas.usp.br/tradterm 
Delata o seu egocentrismo ao esquecer-se dos próprios erros, sejam na construção do ser, sejam nas responsabilidades 'paternas' que nega ao abandoná-lo. Assim, o Dr. Victor Frankenstein passa por um processo de desconstrução e perda para poder ter uma visão de os próprios atos; desde o princípio não acredita ser a causa de todas as suas lamentações, culpando a Criatura, tratando-a como uma oposição à sua felicidade, sem ver nenhum traço de humanidade nela. O processo de perda é resultado justamente do ódio da Criatura por ter sido abandonada.

Contudo, a reflexão da própria criatura não pode ser deixada de lado, uma vez que ela passa pelo mesmo processo que Victor. No momento em que isso acontece, vemos mais um lado do ser, uma emoção humana explícita que o faz ser ressignificado em relação ao 'monstro', mas como ‘homem':

Nesse momento, em que já tem consciência de seus atos e já sofreu as consequências de sua ânsia desmedida, o Dr. Victor tem condições de perceber que os novos tipos e limites do agir exigem uma ética de previsão e responsabilidade compatíveis com esses limites, que seja tão nova quanto as situações com as quais tem que lidar (RUIz 2009: 4).

Segundo Cristiane Ruiz (2009: 5), depois de passar por uma série de tragédias pessoais, o Dr. Victor Frankenstein descobre por si mesmo as consequências de suas atitudes. O criador compreende que o caminho seguido o levaria por uma estrada tortuosa; e após a criação de um ser feito de várias partes humanas, Victor Frankenstein se apavora quando vê o resultado de sua experiência. Abandonando sua criatura, Victor tenta se esquecer dos horrores que presencia e da sensação de sucesso que se torna assombrosa ao tornar-se real, viva.

Outro aspecto interessante é a relutância de Victor Frankenstein em escutar a história do monstro. Está sempre de pé atrás, sempre receoso do poder persuasivo da história de vida e da força da argumentação do monstro, talvez porque sabia e reconheceria ex imo corde que, ao ser confrontado com a narrativa da vida e das experiências do monstro, no limite, a culpa era mais sua do que do monstro em relação a tudo o que aconteceu. A narrativa do monstro era um espelho no qual não se queria ver refletido (ARAÚjo; GUIMARÃES 2014: 7).

TradTerm, São Paulo, v.38, fevereiro/2021, p. 337-360

Número Especial - III JOTA

www.revistas.usp.br/tradterm 
Ruiz (2009), Araújo e Guimarães (2014) trazem mais observações sobre as responsabilidades de Victor como pai criador. Quando a Criatura, já com faculdades humanas mais desenvolvidas o reencontra, implora-lhe que ouça seu pedido, antes de ser eliminada. Quer saber a razão de ter sido abandonada, e pede uma companheira: sente-se só. No trecho abaixo, o monstro reconhece sua natureza abjeta, identificando-se mais com Satã do que Adão², questionando o criador por sua própria criação:

Não terei sofrido o bastante para que você aumente minha desgraça? A vida, ainda que possa ser apenas um repositório de angústias, é cara a mim e a defenderei. [...] Sou sua Criatura e serei manso e dócil com meu senhor e rei natural se também quiser cumprir sua parte, a parte que me deve. Oh, Frankenstein, não seja justo com todos os outros e somente maltrate a mim, a quem está obrigado a conceder ainda mais justiça e até clemência. Lembre-se de que sou sua Criatura. Deveria ser seu Adão, mas, em vez disso, sou um anjo caído a quem afastou da alegria sem, no entanto, ter cometido nenhuma falta. Em todo lugar vejo a felicidade dada que somente a mim é irrevogavelmente negada (SHELLEY 2017: 113).

A Criatura vê a si mesma como uma falha e monstruosa, não se reconhece como uma 'conquista'. Victor é incapaz de ver qualidades em sua criação, sente somente repulsa. Victor não sente nenhuma satisfação em ter criado o monstro - que, visto sob o aspecto estético, é uma manifestação da 'beleza horrível' em sua combinação de elementos. Para Victor ele somente é um 'demônio', um ser repulsivo.

Alberto Filipe Ribeiro de Abreu Araújo e Armando Rui Castro de Mesquita Guimarães (2014: 21) defendem que, com a falta de contato físico e com o afastamento humano, a Criatura desenvolveu repúdio a si mesma devido às características que a faziam diferente dos outros. Tudo o que foi visto pelo ser foi absorvido e remodelado dentro da própria psique. Sob este pressuposto, vê-se no poder de rebater as atitudes humanas utilizando delas mesmas, enfim, pondo a causa em Victor, o criador que a abandonou, cujas responsabilidades são negadas de si e recaem sobre a criatura.

\footnotetext{
2 Podemos observar que, na visão dos românticos, Satã é um ser rejeitado, uma espécie de pária, assim como a Criatura.
}

TradTerm, São Paulo, v.38, fevereiro/2021, p. 337-360

Número Especial - III JOTA

www.revistas.usp.br/tradterm 
O indivíduo, desprovido de conhecimentos simples, precisa aprendê-los para sobreviver e fazer durar esta 'vida' que recebeu. Percebe-se que, mesmo sendo uma criatura 'recém-nascida', tem um ótimo domínio de intelecto ao desenvolver por si só reflexões que, para os outros, são comuns, mas para ela se assemelham ao aprendizado de uma criança, como aquecer-se ao fogo sem tocá-lo. Destacamos aqui o aspecto metafórico e até mesmo filosófico da obra, usado como artifício pela autora para expressar a sensação de abandono do monstro, assim como a exclusão social, o que a torna má e vingativa.

Contudo, ao fazer o seu primeiro contato com humanos e compreender mais sobre si mesma, horroriza-se com a própria imagem, aceitando-a como monstruosa:

a Criatura, por ser anormal, monstruosa e feia, não mais é reconhecida como um semelhante e por ser diferente, acabou sendo excluída, expulsa, repudiada e odiada. Vê-se que não há lugar para a tolerância e para o acolhimento daquilo que é diferente, e isso é visível na reação dos filhos do velho de Lacey, que não conseguem evitar a repugnância que a visão do monstro lhes inspira (ARAúJO 2014: 07).

Araújo (2014: 21) justifica que, por sua aparência, a Criatura é deixada de lado e retratada como monstro, fato que influencia sua autoestima e como se aceita ou encara a própria existência. Decide pensar sobre tais aspectos que a cercam e sobre a sociedade, os humanos, intolerantes a qualquer anormalidade. Com isso, sente-se igual e diferente dos outros seres e parece identificar em tais características o medo de ficar para sempre sozinha.

A linguagem, como vista por Marciano Adílio Spica (2015: 4), seria o alicerce para tudo o que a Criatura de Frankenstein adquire: sua noção de mundo, o entendimento das coisas ao redor, seu processo de autoconhecimento. Além disso, antes de obter uma gramática de linguagem pragmática, adquirida pelo que ouve e pela necessidade de conhecer o mundo em que vive; e, possivelmente, confrontar Victor eventualmente, colocandose de igual para igual, e fazer parte da sociedade, a Criatura também tem acesso ao conhecimento oportunizado pela maleta de livros encontrada e os pensamentos que a levam a adquirir intelecto suficiente para dominar suas delimitações.

TradTerm, São Paulo, v.38, fevereiro/2021, p. 337-360

Número Especial - III JOTA

www.revistas.usp.br/tradterm 
O fato de a criatura dominar a linguagem não a torna capaz de se incluir na sociedade - este é o aspecto mais irônico do romance. Pois, apesar de ela se comunicar às vezes com bastante erudição, não cria empatia com ninguém. Somente se comunica com o velho Lacey por ele ser cego. Além disso, não são somente os livros que a fazem adquirir intelecto. A Criatura já nasce com uma imensa capacidade de aprender e assimilar aspectos da realidade. 0 que ela não consegue é usar isso ao seu favor para se inserir na sociedade.

A personagem não se vê como culpada, mas como se dividisse a culpa por todos os atos com o criador, deixando-a no limbo, para morrer sozinha, sem perceber que o 'monstro', como a chama, poderia evoluir, embora os sofrimentos sejam tanto da criatura como de seu criador. Neste aspecto, ambos são figuras prometeicas por desafiarem autoridades superiores: Victor desafia 'Deus' e as Leis da Natureza, por isso sua criação também sofre o castigo devido a sua monstruosidade; por sua vez, a Criatura desafia o seu criador, Victor.

Por um lado, se Victor não abandonasse a sua Criatura, haveria outro nível de educação: a teoria de Victor, sobre a Criatura ser puro mal seria revista, de um ponto de vista evolutivo em relação ao aprendizado dessa por seu pai-criador.

\section{As transposições fílmicas}

Quase duzentos anos após seu lançamento, a obra de Mary Shelley é um dos marcos mais importantes da cultura Pop, principalmente nos gêneros Horror, Terror e Ficção Científica. Inúmeras adaptações foram feitas para o teatro e o cinema- e perduram até hoje. De acordo com Lucas e Rodrigues (2017: 2):

Tal fenômeno se dá não apenas por seguidas adaptações do romance, mas também pela apropriação de personagens e elementos da trama. Seja na figura do cientista louco, do monstro criado em laboratório ou das tragédias engendradas pela busca imprudente do conhecimento, o romance de Shelley se mantém vivo e atual.

TradTerm, São Paulo, v.38, fevereiro/2021, p. 337-360

Número Especial - III JOTA

www.revistas.usp.br/tradterm 
Na transposição fílmica Frankenstein (WHALE 1931), a história se inicia com Frankenstein e seu ajudante, Fritz ${ }^{3}$ escondidos em um cemitério durante um funeral. Mais tarde, os dois desenterraram o corpo e o usam nas experiências do cientista.

No começo, nota-se como os personagens de Shelley e Whale aparentam ter pouco em comum, a começar pelos nomes. Victor foi transformado em Henry - melhor amigo do cientista, Henry Clerval; outro personagem de Shelley, foi nomeado com o seu nome. Henry Frankenstein é o protagonista clássico desse gênero: um cientista maluco e caricato que anseia acima de tudo realizar sua pesquisa e seus experimentos. Em seu olhar há um quê mais psicótico que genial, manifestado nas diversas falas do personagem. O filme, intitulado Frankeinstein, e por ser o nome do cientista pouco mencionado, contribuiu para a confusão com o nome do monstro, aumentada com o lançamento da sequência, A noiva de Frankenstein (1935), filme que se apropria de elementos à criação de uma companheira para o monstro, presentes na obra literária.

Saindo do cemitério, Henry e seu ajudante acham outro corpo, enforcado e com o pescoço quebrado e precisam encontrar um e cérebro. Fritz invade a Faculdade de Medicina e rouba um cérebro defeituoso e corroído, fator que, no filme, leva a experiência a ser um total fracasso: a Criatura é limitada e somente se comunica com gestos e sons guturais.

Uma das características mais marcantes dessa adaptação fílmica é o processo de criação de vida. Na cena em que Henry dá vida à sua Criatura, cercado por Victor Moritz (Henry Clerval na obra literária), Elizabeth, noiva de Frankenstein, e o Doutor Waldman, professor da faculdade de Medicina Ingolstadt - todos preocupados com a sua sanidade mental -, ele se regozija em êxtase psicótico. 0 seu experimento cria vida em matérias mortas através de energia elétrica transmitida pelos raios em uma noite tempestuosa. No livro, contudo, Frankenstein se abstém de revelar o processo, alegando que

\footnotetext{
${ }^{3}$ Personagem não existente no livro, mas recorrente em adaptações, assim como o corcunda Igor, uma invenção do filme de Whale, que aparece em Victor Frankenstein (2015).
}

TradTerm, São Paulo, v.38, fevereiro/2021, p. 337-360

Número Especial - III JOTA

www.revistas.usp.br/tradterm 
nenhum outro ser deveria perpetrar os seus mesmos horrores. Tais representações podem ter sido inspiradas pela própria Shelley:

Para a composição de sua novela, Mary Shelley se apropria do conhecimento científico e médico disponível na época. Entre as principais influências estão os experimentos de Erasmus Darwin, avô de Charles Darwin, estudioso das correntes galvânicas, estímulo no qual um feixe elétrico contínuo e polarizado é aplicado sobre tecido orgânico provocando contrações em tendões e músculos. Embora não tenha chegado a reanimar cadáveres, é utilizada até hoje como uma forma de eletroterapia em tratamentos estéticos. Erasmus Darwin chega a ser citado no prefácio, na introdução, pela autora, e no texto da obra, pela personagem Victor Frankenstein, que faz referência a um sábio inglês, cujos estudos contribuiriam para o sucesso de seu experimento (LUCAS; RODRIGUES 2017: 03).

Após criar vida, Henry embarca na segunda parte de seu experimento: analisar sua criação. Esta, um ser alto com parafusos no pescoço e intelecto diminuto, representação física e mental da figura criada por Whale (1931), inicialmente é livre para pelos limites da morada do cientista, enquanto estuda e pesquisa. Na verdade, a imagem do monstro é o resultado do trabalho do maquiador Jack Pierce, não tanto de Whale, pois foi de Pierce a ideia de colocar parafusos dos lados do pescoço para traduzir a associação do monstro com a eletricidade.

Diferente de Victor Frankenstein, o Henry, de James Whale não ignora a genialidade de sua criação, tampouco se prende à estética aterrorizante de sua Criatura. Por outro lado, Henry se vê fascinado com cada movimento feito, dialogando com o Ser e guiando-o a realizar atos básicos, satisfeito ao notar ser entendido.

TradTerm, São Paulo, v.38, fevereiro/2021, p. 337-360

Número Especial - III JOTA

www.revistas.usp.br/tradterm 
Figura 1: Frankenstein. Direção: James Whale. Universal Studios, 1931

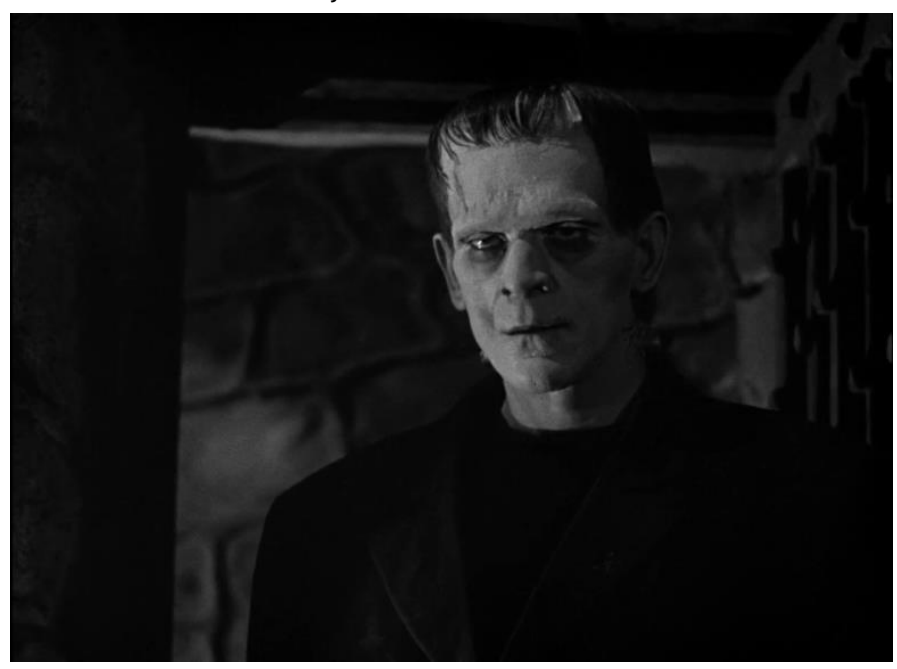

Porém, quando o ajudante Fritz reaparece segurando uma tocha, a Criatura responde apavorada em um ataque de fúria impedido por Henry, Dr. Waldman e o ajudante, e é isolada em uma das celas na torre. O entusiasmo de Henry diminui ao perceber não ser capaz de lidar com sua criação, embora continue mostrando algo semelhante a afeto por ela, subjugada por Fritz, o qual atiça a Criatura durante seus ataques de violência. Tão logo os sentimentos de Henry surgem, desaparecem ao ver seu ajudante enforcado pelo agora denominado 'monstro'.

Assim como o Victor literário adoece, Henry também fica doente e é levado para casa. Porém, a Criatura é cuidada pelo Dr. Waldman, e logo o mata. Em casa, Henry está prestes a se casar, enquanto a Criatura se desenvolve sozinha, desbravando o mundo além das paredes da torre, tendo o seu primeiro encontro com a humanidade através de uma garotinha que lhe ensina como as flores flutuam no rio. A Criatura, intelectualmente deficiente, joga sua amiguinha no rio, esperando que flutuasse como as flores, mas ela se afoga.

Na obra literária, o primeiro encontro é com o velho De Lacey e os seus filhos, que, dominados pela aparência monstruosa, com exceção do pai, por ser cego, demonstram um dos primeiros atos de ódio da sociedade e os seus conceitos em relação à estética. Porém, de uma forma ou de outra, ambos os acontecimentos fazem a Criatura ir até o seu criador.

TradTerm, São Paulo, v.38, fevereiro/2021, p. 337-360

Número Especial - III JOTA

www.revistas.usp.br/tradterm 
O encontro de Elizabeth, a noiva de Frankenstein, com a Criatura é construído de forma diferente em ambas as obras. Whale (1931) utilizou de um artifício maior para a composição da adaptação. 0 primeiro encontro no laboratório de Henry não existe em Shelley, uma vez que o cientista está só no momento de sua criação, mas nesse filme, Elizabeth está viva após o encontro com o 'monstro' em sua casa e sabe da existência do ser, ao contrário da personagem literária, cuja morte é narrada por Shelley como um dos pontos mais importantes para a concepção da vingança de Victor:

Nada é tão doloroso para mente humana como uma grande e súbita mudança. O sol poderia brilhar, as nuvens poderiam baixar, mas nada pareceria como no dia anterior. O demônio arrebatara-me qualquer esperança de felicidade; nenhuma Criatura jamais fora tão miserável quanto eu. Um acontecimento tão medonho é único na história do homem (SHELLEY 2017: 203).

$\mathrm{Na}$ obra fílmica, ainda sem a morte de Elizabeth, o criador decide caçar a sua Criatura. Henry é o primeiro a encontrar o 'monstro', mas é nocauteado por ele e levado até o moinho de vento. ${ }^{4}$ Além disso, pressupõe-se que o objetivo de Whale (1931) seria mostrar a dualidade do bem e do mal a partir de outra perspectiva, visto que, após tudo, Henry continua vivo enquanto a Criatura perece no incêndio causado pelos civis indignados com a morte da garotinha e $o$ ataque a Elizabeth.

0 final feliz em que Victor se casa com Elizabeth, construído por Whale, não existe na obra de Shelley. Nesta, seu protagonista perde tudo e, sua saúde piora, mas pouco antes de morrer, ao falar com o Capitão Walton, Victor se arrepende:

Durante estes últimos dias estive ocupado em examinar minha conduta passada, não que a creia censurável. Em um achaque de loucura apaixonada, criei uma criatura racional e estava comprometido a assegurar-lhe a obrigação de lhe garantir, até onde estava o meu alcance, sua felicidade e bem-estar (SHELLEY 2017: 221).

\footnotetext{
${ }^{4} \mathrm{O}$ moinho de vento se transformou em referência para filmes como Frankenweenie (2012), de Tim Burton. Frankenweenie é uma referência direta a Frankenstein (SHELLEY, 1931) e narra a perspectiva de Victor Frankenstein como um garoto aspirante à cientista que, após perder 0 seu cachorro e melhor amigo em um atropelamento, decide revivê-lo usando do mesmo processo de Henry Frankenstein para conceber a sua Criatura.
}

TradTerm, São Paulo, v.38, fevereiro/2021, p. 337-360

Número Especial - III JOTA

www.revistas.usp.br/tradterm 
Victor não nega ter se ausentado da vida de sua Criatura e assume a responsabilidade de seus atos, percebendo que estava no dever de ter guiado o 'filho'. Em seus últimos momentos, Victor também admite que uma de suas maiores angústias é que "ele viva para ser um instrumento do mal" (SHELLEY 1831: 223). Ademais, assim como o seu criador, ao ver o corpo de Frankenstein, a Criatura também se enche de pesar em relação a Victor, revelando ao Capitão Walton os seus arrependimentos:

Ele não sofreu na consumação da façanha. Oh! Nem um décimo milésimo do que foi a minha angústia durante o prolongado pormenor de sua execução. [...] Pensa que os gemidos de Clerval foram música para meus ouvidos? Meu coração foi feito para ser suscetível ao amor e à compaixão e, quando conduzido pela infelicidade ao vício e ao ódio, não suportou a violência da mudança sem afligir-se de um modo que jamais poderá imaginar (SHELLEY 2017: 223).

Shelley reforça ao final que o bem e o mal existem na natureza humana e que tanto a criatura como se criatura em alguma medida tinham isso dentro de si.

A obra mais recente, Victor Frankenstein foca na personagem homônima, fazendo uma leitura da obra de Shelley por um viés semelhante ao filme de Whale, apesar do tipo de aproximação entre os dois filmes com o texto literário. Considerando que a personagem do lacaio, ou ajudante, é bastante recorrente em outros filmes 'góticos', consideramos que apenas o filme de McGuigan reproduz isso, estabelecendo alguns pontos de contato, no aspecto visual, com a produção de 1931.

A adaptação de 2015 explica a origem do ajudante Igor, corcunda assim como o Fritz de Henry Frankenstein. Ele veio de um circo, considerado aberração por sua disfunção corpórea. Igor é rejeitado por todos, exceto pela equilibrista Lorelei, por quem se apaixona. Ela sofre um acidente circense, e Igor demonstra conhecimentos de medicina ao salvá-la com a ajuda de um médico que assiste ao espetáculo, Victor Frankenstein. Encantado, Victor o ajuda a fugir do circo, recrutando-o como ajudante para o projeto de sua vida: a animação de matérias mortas.

TradTerm, São Paulo, v.38, fevereiro/2021, p. 337-360

Número Especial - III JOTA

www.revistas.usp.br/tradterm 
Apesar de empenhar-se em manter o foco em Victor, o filme Victor Frankenstein apresenta o médico cientista pelos olhos de Igor, como narrador da adaptação. 0 ajudante seria o protagonista da obra fílmica, pois seu amor por Lorelei é demonstrado veementemente, enquanto a personalidade de Victor é denotada como um aspecto por seu caráter insano e duvidoso na busca pela criação da vida. Além disso, Igor não é realmente corcunda: um abscesso causava um grande edema por falta de tratamento. Victor drena a secreção das costas de seu ajudante em uma cirurgia rápida, coloca nele um aparelho para corrigir sua postura, curando-o.

Um dos pontos importantes a se comparar nessa nova versão é como a ciência de Victor é mostrada: em uma exposição na universidade onde estuda Medicina, com seu primeiro teste, um símio construído de partes de animais denominado Gordon desperta de forma caótica e é morta após perderem controle sobre o animal. A exposição não é de todo maléfica para Victor e lgor, visto que um homem de alta sociedade, rico e ganancioso, chamado Finnegan, ${ }^{5}$ fica interessado pela invenção e promete ajuda monetária para uma nova criação: um homem. Contudo, sendo procurados pela fuga do circo, pois uma pessoa havia sido morta, o Inspetor Turpin, que rege o caso, fanático religioso assim como Finnegan, encontra novos indícios dos crimes de Victor e Igor e inicia uma busca incessante para prendê-los, impedindo o que considera blasfêmia a Deus. Esta adaptação mostra o embate Ciência vs. Religião, um dos temas centrais de Frankenstein. Não seriam os 'conceitos religiosos' de Victor na obra que o motivam a dar vida à Criatura, mas a visão cientificista, negando a existência de uma autoridade superior 'Deus'.

As discrepâncias entre o livro e o filme de Mcguigan parecem bastante explícitas, uma vez que a vida de Victor não é apresentada e até mesmo sua paixão por Elizabeth e sua família é deixada de lado. 0 único momento do seu passado é ilustrado pelo aparecimento de seu pai, desapontado com os rumores sobre o filho Victor e suas 'criações insanas', culpando-o pela morte de seu irmão que, nesta nova adaptação, chama-se Henry Frankenstein, o Henry Clerval de Shelley. Essa é também é a justificativa para Victor criar o Ser: ressentimento.

\footnotetext{
${ }^{5}$ Personagem inexistente em Shelley.
}

TradTerm, São Paulo, v.38, fevereiro/2021, p. 337-360

Número Especial - III JOTA

www.revistas.usp.br/tradterm 
A criação se dá pelos mesmos processos utilizados no filme de 1931, a corrente elétrica produzida pela tempestade de raios, com instrumentos aparentemente superiores aos de Henry Frankenstein de 1831. A nova Criatura (Fig. 2) se baseia na aparência criada para a adaptação anterior (Fig.1), com os parafusos dispostos no pescoço, a cabeça achatada, de pele amarela e desfigurada. Entretanto, a Criatura também só aparece completamente ao final da adaptação, no momento de redenção de Victor: ele fica diante de sua criação e a chama de irmão.

Figura 2: Victor Frankenstein, dirigido por Paul Mcguigan. Twentieth Century Fox Studios, 2015.

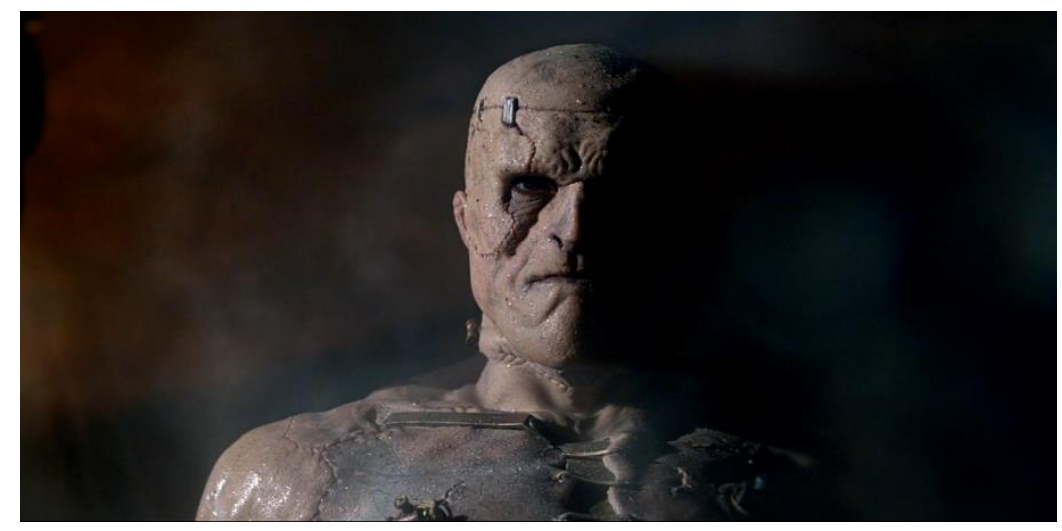

Nesse mesmo momento, Victor encara a Criatura, percebe o erro que cometera, declarando que o que estava diante de si não era 'uma pessoa com vida, de verdade'. Victor perde controle da Criatura e, assim, inicia a subjugação daquilo agora considerado monstro. Esse ser age por desmedida raiva e inconsciência, apenas destruindo tudo à sua frente, portanto, assim como é criada, a Criatura é rapidamente destruída por Victor e Igor.

Em Shelley obra é narrada pelo Capitão Walton, Victor Frankenstein e a Criatura. O momento de criação da Criatura não é mencionado, pois Victor não quer mais alguém passe pelo seu mesmo 'horror'. Além disso, a Criatura possuiu intelecto adquirido, sabe sobre si e sobre a sociedade que a cerca.

$\mathrm{Na}$ obra dirigida por Whale, as identidades de Victor Frankenstein e Henry Clerval estão trocadas: Victor se transforma em Henry Frankenstein, o cientista; Henry em Victor Moritz, seu melhor amigo. Fritz, o ajudante corcunda é adicionado como a personagem motivadora do primeiro rompante

TradTerm, São Paulo, v.38, fevereiro/2021, p. 337-360

Número Especial - III JOTA

www.revistas.usp.br/tradterm 
assassino da Criatura. Ademais, essa nova Criatura tem traços cômicos, sem a mesma capacidade intelectual da Criatura de shelliana.

Quanto a Victor Frankenstein, apesar do título, o filme não é narrado através do ponto de vista dessa personagem, mas por lgor, seu ajudante, equivalente a Fritz de 1931. A Criatura, nesse filme do início do século XX, um ser com deficiência intelectual e potencial destruidor, redime Victor do remorso que sente da morte de seu irmão, Henry Frankenstein.

\section{Considerações finais}

Buscamos evidenciar, a partir das adaptações fílmicas, a intertextualidade entre o romance de Shelley e os filmes de 1931 e 2015, destacando possíveis áreas de convergência e divergência de significado entre o texto literário e filmes adaptados

A essência da personagem de Victor é mantida, com divergências. Primeiramente, Victor Frankenstein e seu melhor amigo, Henry Clerval, trocam de nomes em Frankenstein (WHALE 1931). Neste Henry, a ânsia científica beira a insanidade, e a personagem representa o papel de 'cientista louco' como justificativa para o Terror, gênero escolhido para a adaptação. A criatura, ou o monstro criado, um ser com deficiência intelectual, destaca no filme a sua monstruosidade no aspecto físico, e, por algumas vezes, serve como alívio cômico, artifício usado para atenuar a violência de algumas sequências, como o afogamento da menina no lago.

Além disso, ressalta-se também a introdução de uma personagem nova: Fritz, o assistente que se tornou referência para outras adaptações, como Igor de Victor Frankenstein. Neste filme, apesar de narrar a história, Igor foca-se em Victor e sua personalidade como gênio excêntrico, elucidando seu trajeto e meios ilícitos utilizados na criação de seu 'Prometeu', que, difundido por Mary Shelley, referia-se ao próprio Victor, como corruptor de leis e sentenciado por isso, considerando os aspectos prometeicos encontrados no criador e sua Criatura.

TradTerm, São Paulo, v.38, fevereiro/2021, p. 337-360

Número Especial - III JOTA

www.revistas.usp.br/tradterm 
No Frankenstein dirigido por Whale, o insano e visionário cientista manda seu criado procurar um cérebro para sua criatura, e a ama antes de perder o controle sobre ela e denominá-la 'monstro'. O filme Victor Frankenstein mostra um Victor excêntrico e singular, retira explicitamente a imagem da Criatura, exibida apenas no clímax do filme, justificando a redenção do cientista. Esta goza dos mesmos artifícios estéticos que consagram o 'Monstro de Frankenstein' pelo ponto de vista do filme de 1931 um humanoide gigantesco, de pele pálida e amarelada, cabeça achatada, criado pela energia de raios, responsável pela estética em adaptações subsequentes, e a repetição de um monstro ignorante. Essa imagem é propriedade do estúdio Universal, e foi adaptada nesse filme ${ }^{6}$.

Ambas as adaptações desenvolveram seus personagens não à luz de Shelley, mas por um imaginário diferente, interessado em causar medo e agonia, focando em conceitos estéticos, em prol de evidenciar o gênero Horror. Shelley criou o Horror a partir da atmosfera de ficção e realidade: daí os conceitos de ficção científica, pela não adição do sobrenatural, a idealização do homem como um ser criador de vida, não meramente apenas na figura do 'monstro' ou nas emoções de Victor. As adaptações, portanto, afastam-se da obra escrita, realizando duas leituras igualmente diferentes.

${ }^{6}$ Ressaltamos que a imagem do monstro em Frankenstein de Mary Shelley é mais próxima à descrição feita pela autora do livro.

TradTerm, São Paulo, v.38, fevereiro/2021, p. 337-360

Número Especial - III JOTA

www.revistas.usp.br/tradterm 


\section{Referências}

Araujo, A. F. O monstro de Frankenstein: uma leitura à luz do imaginário educacional. Revista Temas em Educação, 23 (1), p. 14-35, 2014. Disponível em:

<https://periodicos.ufpb.br/ojs2/index.php/rteo/article/view/18790 >. Acesso em: 12 jan. 2021.

Araújo, A. F. R. A.; Guimarães, A. R. C. M. Victor Frankenstein, um Prometeu moderno? Sob o olhar do imaginário educacional. Letras \& Letras, v. 30, n. 1, p. 18-37, dez. 2014. Disponível em: <http://www.seer.ufu.br/index.php/letraseletras/article/view/27353 >. Acesso em: 12 jan. 2021.

Costa, A. A propaganda na pós-modernidade: uma perspectiva de identidades partilhadas. In: SACRAMENTO, S. (Org.). Comunicação e mídia: análise do discurso e formação discursiva em textos midiáticos. Ilhéus, BA: Editus, 2004. p.11-18.

FrankENWEenIE. Direção: Tim Burton. Produção: Walt Disney Pictures. Intérpretes: Wynona Rider, Catherine O'Hara, Martin Short, c. 2012. DVD $(87 \mathrm{~m})$.

HutCHEON, L. A Theory of Adaptation. New York: Routledge, 2006.

JEHA, J. Veja o livro e leia o filme. Revista Todas as letras, n. 6, p. 123. 2004. Disponível em: <www.juliojeha.pro.br/sign_res/InterTransPtg.pdf>. Acesso em: 12 jan. 2021.

LUCAS, R. J. L.; RodRIgUES, F. L. Frankenstein: a trajetória errante de um monstro narrativo. Revista Passagens, v. 8, n. 1, p. 19-44, 2017. Disponível em: <http://www.periodicos.ufc.br/passagens/article/view/20249>. Acesso em: 12 jan. 2021.

McGuigan, P. Victor Frankenstein. Direção: Paul McGuigan. Produção: Derek Dauchy e Ira Schuman. Estados Unidos da América: Twentieth Century Fox Studios, 2015.

PlazA, J. Tradução Intersemiótica. $1^{\text {a }}$ ed. São Paulo: Perspectiva, 2003.

RuIz, C. R. Frankenstein de Mary Shelley e sua mensagem perene sobre a responsabilidade da ciência sob a luz da Bioética. Arq Bras Ciên Saúde, Santo André, v. 34, n. 3, p. 196-200, set./dez. 2009. Disponível em:

<https: / /www.portalnepas.org.br/abcs/article/view/124>. Acesso em: 12 jan. 2021.

Shelley, M. Frankenstein ou O Prometeu Moderno. Tradução de Márcia Xavier de Brito. Rio de Janeiro: DarkSide Books, 2017.

TradTerm, São Paulo, v.38, fevereiro/2021, p. 337-360

Número Especial - III JOTA

www.revistas.usp.br/tradterm 
SPICA, M. A. Linguagem e dignidade: um ensaio a partir de Frankenstein de Mary Shelley. Revista Espaço Acadêmico, n. 171, p. 92-103, ago. 2015.

WESONGA, R. O. Nexus between literary texts and corresponding film adaptations: a reading on intertextuality. Disponível em: http://irlibrary.ku.ac.ke/handle/123456789/18370. Acesso em: 12 jan. 2021.

WHALE, J. Frankenstein. Direção: James Whale. Produção: Carl Laemmle. Estados Unidos da América: Universal Studios, 1931.

Recebido em: 29/04/2020

Aceito em: 03/12/2020

Publicado em fevereiro de 2021

TradTerm, São Paulo, v.38, fevereiro/2021, p. 337-360

Número Especial - III JOTA

www.revistas.usp.br/tradterm 